SJ Quinney College of Law, University of Utah Utah Law Digital Commons

Utah Law Faculty Scholarship

Utah Law Scholarship

Spring 2017

\title{
Essentiality and Standards-Essential Patents
}

Jorge L. Contreras

S.J. Quinney College of Law, University of Utah, jorge.contreras@law.utah.edu

Follow this and additional works at: http://dc.law.utah.edu/scholarship

Part of the Intellectual Property Law Commons

\section{Recommended Citation}

Cambridge Handbook of Technical Standardization Law - Antitrust, Competition and Patent Law (Jorge L. Contreras, ed., 2017 Forthcoming)

This Book Chapter is brought to you for free and open access by the Utah Law Scholarship at Utah Law Digital Commons. It has been accepted for inclusion in Utah Law Faculty Scholarship by an authorized administrator of Utah Law Digital Commons. For more information, please contact valeri.craigle@law.utah.edu. 


\title{
ChAPTER 13
}

\section{ESSENTIALITY AND STANDARDS-ESSENTIAL PATENTS}

\author{
Jorge L. Contreras ${ }^{1}$
}

A. Origins of the Essentiality Requirement 2

1. SDO POLICIES 2

2. ESSENTIALITY AND PATENT POOLS

B. The Many Meanings of Essentiality 8

1. Claims VERSUS PATENTS 8

2. COMMERCIAL VERSUS TECHNICAL ESSENTIALITY 9

3. ESSENTIALITY OF MANDATORY AND OPTIONAL PORTIONS 13

4. TIMING AND ESSENTIALITY 14

C. Essentiality and Over-Declaration 15

1. FACTORS LEADING TO OVER-DECLARATION $\quad 15$

2. QUANTIFYING OVER-DECLARATION 17

3. PRoposals to AddRESS OVER-DEClaration 17

D. Challenges to Essentiality 18

1. COMPETITION LAW ENFORCEMENT - SUN/ETSI (EC) 18

2. JUDICIAL DECLARATION OF NON-ESSENTIALITY - NOKIA V. INTERDIGITAL (UK) 19

3. ESSENTIALITY ASSERTED BY PATENTEE - UNWIRED PLANET V. HUAWEI (UK) 19

4. ESSENTIALITY OF MULTIPLE PATENTS - IN RE. INNOVATIO (U.S.) 20

5. ESSENTIALITY IN TOP-DOWN ROYALTY ALLOCATIONS - TCL V ERICSSON (U.S.)21

As discussed throughout this volume, most standards-development organizations (SDOs) have adopted policies requiring that participants either disclose and/or license patents that are essential to the implementation of the SDO's standards. ${ }^{2}$ Licenses of these standards-essential patents (SEPs) must generally be royalty-free or royaltybearing on terms that are fair, reasonable and non-discriminatory (FRAND). Conversely, patents that are not essential to such standards need not be licensed on reasonable terms, and in theory may be withheld entirely from the market. Accordingly, a key element of SDO disclosure and licensing polices is how patents (or patent claims) are classified as "essential" to a standard, and what essentiality entails in practice. This chapter addresses the interpretation of the term "essential" within SDO patent policies, focusing both on policy language and variants, as well as regulatory and judicial rulings that have considered this question.

${ }^{1}$ Associate Professor, University of Utah S.J. Quinney College of Law. The author thanks Christian Loyau and Michael Mattioli for their assistance and helpful comments during the preparation of this chapter. Please send comments, corrections and suggestions to jorge.contreras@law.utah.edu.

2 Some SDO's use the term "necessary" in lieu of "essential." For the most part, these terms are synonymous. See ABA 2007, 10. 


\section{Essentiality}

\section{A. Origins of the Essentiality Requirement}

This section traces the emergence and growth of essentiality requirements for patents covering elements of technical standards. It first describes the evolution of essentiality requirements in the patent policies of the American National Standards Institute (ANSI), the European Telecommunications Standards Institute (ETSI) and the Institute of Electrical and Electronics Engineers (IEEE), three large and globally influential organizations that have devoted significant attention to their patent policies. It then addresses the parallel evolution of essentiality requirements in standards-based patent pools, an evolution that clearly influenced what was happening within SDO patent policy committees.

\section{SDO Policies}

a) ANSI

The earliest SDO patent policies did not include express requirements relating to the essentiality of patents. As discussed in Chapter 9, the American Standards Association's (ASA) 1959 policy, generally considered to be the first SDO FRAND licensing policy, ${ }^{3}$ required that "[s]tandards should not include items whose production is covered by patents unless the patent holder agrees to and does make available to any interested and qualified party a license on reasonable terms..." ${ }^{4}$ Thus, the ASA policy applied to patents covering the production of standardized items, though the term "covering" was not elaborated in any detail.

ASA became the American National Standards Institute (ANSI) in 1969. In policies adopted from 1969 through 1977, ANSI retained ASA's "covering" language, requiring that if a standards-developer held a patent "covering any invention the use of which would be required for compliance with the proposed [standard]", the patent must be licensed to applicants desiring to implement the standard. ${ }^{5}$ The use of "covering" was discontinued in ANSI's 1983 policy in lieu of a more detailed description of "any invention the use of which would be required for compliance with the proposed [standard]." This formulation continued through multiple revisions of ANSI's policy through $2006 .{ }^{6}$

It was not until IEEE introduced the idea of "essential" patent claims in its controversial 2006-07 policy ${ }^{7}$ that ANSI followed suit. Thus, in January 2007 ANSI introduced the concept of "essential" patent claims to its policy, which provides that:

There is no objection in principle to drafting an American National Standard (ANS) in terms that include the use of an essential patent claim (one whose use would be required for compliance with that standard) if it is considered that technical reasons justify this approach.

Likewise, Section 3.1.1 of ANSl's 2007 policy first required licensing of "essential patent claims" with or without compensation and otherwise on "reasonable terms and

\footnotetext{
3 See Chapter 9.

${ }^{4}$ ASA 1959, § 11.6.

${ }^{5}$ See GTW Assoc. 2015 (summarizing evolution of policies).

${ }^{6}$ ld.

${ }^{7}$ See Part A.1.c below.
} 


\section{Essentiality}

conditions that are demonstrably free of any unfair discrimination." ${ }^{8}$ But by 2007 , ANSI was a relative latecomer to the definition of essentiality. As discussed below, ETSI had already implemented this requirement a decade and a half earlier.

\section{b) ETSI}

As discussed in Chapter 9, the major European national telecommunications operators began to cooperate in the early 1980s to develop the emerging GSM "2G" cellular wireless communications protocol intended to replace existing analog networks. In 1985, the German, French and Italian telecom agencies entered into a technical cooperation agreement (the DCR Agreement), which was joined by the UK one year later. ${ }^{9}$ The DCR Agreement established the ground rules for technical cooperation among the four European agencies, requiring, among other things, that if any of their suppliers held a patent "essential" to any element of the GSM standard, then the supplier must grant a "non exclusive free of charge operating license" to any European firm wishing to produce or sell GSM-compliant equipment. ${ }^{10}$ The DCR Agreement goes on to define "essential" patents as:

patents from which the standard is directly derived but also as the patents which could be considered as absolutely necessary for the realization of the standard. ${ }^{11}$

This appears to be the first formal essentiality requirement associated with standardsrelated patents. Though the DCR Agreement was never adopted by an SDO, and merely represented the agreement of four potential users of standardized products, ${ }^{12}$ the princple of essentiality that it reflects was highly influential to later groups.

ETSI, the European Telecommunications Standards Institute, was formed in 1988 at the urging of the European Commission in order to facilitate and accelerate the development of European telecommunications standards. ${ }^{13}$ Given the Commission's heavy involvement in telecommunications deregulation in Europe, it played an active role in defining ETSl's formative policies. As described in Chapter 9, there was significant debate over ETSI's first patent policy. An interim policy was not adopted until 1993, five years after the organization was formed, but it met with so much resistance (largely from U.S. technology vendors), that it was withdrawn. A revised interim policy was finally adopted in November 1994.

Despite the controversy over many provisions of ETSI's 1993 interim policy, its proposed definition of essentiality met little opposition. The 1993 ETSI definition, which is more nuanced than the DCR Agreement's "absolutely necessary" formulation, provides that:

"Essential" as applied to IPR means that it is not possible on technical but not commercial grounds, taking into account normal technical practice and the state of the art generally available at the time of standardisation,

\footnotetext{
${ }^{8}$ ANSI 2007.

${ }^{9}$ Agreement on co-operation in the field of digital cellular radiocommunications, signed in Nice, France, June 20, 1985, extended to the UK on July 2, 1986 (“DCR Agreement").

${ }^{10}$ DCR Agreement 1985, Annex C, Î C.

${ }^{11}$ Id.

12 At this time, GSM was being developed within CEPT, the European Conference of Postal and Telecommunications Administrations. See generally, Bekkers \& Smits 1999, § 6.2.1.

${ }^{13}$ See Besen 1990,
} 


\section{Essentiality}

to make, sell, lease, otherwise dispose of, repair, use or operate equipment or methods which comply with a standard without infringing that IPR. For the avoidance of doubt in exceptional cases where a standard can only be implemented by technical solutions, all of which are infringements of IPRs, all such IPRs shall be considered essential. ${ }^{14}$

This definition, which was adopted verbatim in ETSI's approved 1994 policy, ${ }^{15}$ and which has persisted through the present ${ }^{16}$ addresses several concepts. First, it introduces the important distinction between "technical" and "commercial" essentiality, which is discussed in Part B.2 below. Second, it establishes an absolute "not possible" threshold for compliance. That is, an "essential" patent is one that it is simply "not possible" to work around, as a technical matter, if a product is to be compliant with the standard. This is far more definite, but also more stringent, than a standard such as "not feasible" or "not practical". The end result is that fewer patents will be deemed to be essential under this strict standard (as with the technical essentiality standard discussed below). The final part of the definition addresses the question of alternative implementations, which is discussed in Part B.4 below.

Recall that during the early 1990s, ANSI's definition of essentiality continued to be relatively rudimentary: "required for compliance with the proposed [standard]." As noted above, ANSI does not even introduce the word "essential" to its patent policy until 2006. ETSI's adoption of its much more detailed version of essentiality is likely due to the deep involvement of the Commission, and more than a few corporate legal counsel, in its formation, and the need, from the outset, to take into account competition law principles.

The mandatory character of ETSl's telecommunications standards in Europe made it particularly important to circumscribe carefully the scope of patents that would be committed under ETSI's policies. As the Commission wrote in 1992, "whenever public authorities incorporate standards into legislation and thereby confer upon them a more binding character than their normal voluntary status, they must satisfy themselves that ... the standards in question are available for use by all interested parties". ${ }^{17}$ The importance of "essential" patents is thus elevated in the context of mandatory standards. They act as gatekeepers not only to potentially lucrative commercial markets, as they do in the context of voluntary consensus standards, but as gatekeepers to the only market in the industry: one that is defined by government. For this reason, it is not surprising that the Commission and ETSI devoted significant attention to the definition of "essential" patents in ETSI's earliest patent policies.

\section{c) IEEE}

Unlike their European counterparts, U.S. antitrust enforcement agencies did not actively intervene in the formation of most SDO patent policies. Thus, policy provisions responsive to particular antitrust compliance issues did not enter into the policies of

\footnotetext{
${ }^{14}$ ETSI 1993-Policy, App. A, Annex 1, § 6 (capitalization adjusted).

${ }^{15}$ ETSI 1994-Policy, Annex, § 6.

${ }^{16}$ ETSI 2016, Annex 6, §15(6), p.41.

${ }^{17}$ European Comm. 1992, § 2.3.3.
} 
major U.S. SDOs until prompted by litigation ${ }^{18}$ or requests for review and clearance by antitrust authorities. ${ }^{19}$

The Institute of Electrical and Electronics Engineers (now known as IEEE) began as an early technical trade association in 1884. Standards development at IEEE is conducted through the IEEE Standards Association (IEEE-SA), an operating division that is accredited by ANSI as a developer of American National Standards (see Chapter 9). IEEE standards cover a broad of range of electrical and electronics applications including electrical safety, equipment disposal, batteries, power distribution, computer networking, and communications. Among the best-known IEEE standards are the 802.3 Ethernet standard series and the $802.11 \mathrm{Wi}-\mathrm{Fi}$ wireless networking standards.

Like ANSI, IEEE-SA historically permitted the inclusion of patented technologies in its standards when justified by "technical reasons". ${ }^{20}$ In 1994, IEEE expanded its description of which patents were included within the scope of its policy, stating that a patented technology may be included in an IEEE standard only if, among other things, "there are no alternative methods or devices that can be used to meet the requirements of the standard without infringing on the patent". ${ }^{21}$ This formulation was further refined in 1995 to permit the inclusion of patented technologies if there was "no equivalent, noninfringing way of achieving the objectives of the standard."22

Terminology relating to "essential" patents was not introduced to IEEE's policies until 2005, when IEEE required each holder of a patent or patent application that "might be essential to the implementation of" an IEEE standard to submit a letter committing to license that patent on RF or RAND terms. ${ }^{23}$ But it was not until IEEE's controversial 2006-07 policy amendments that an expansive definition of "Essential Patent Claim" was introduced. ${ }^{24}$ The precise contours of IEEE's recent definitions of essentiality, which distinguishes between "technical" and "commercial" essentiality, are discussed in Parts B.2.b and D.4 below.

\section{Essentiality and Patent Pools}

As discussed in Chapter 8, a number of important standards in the electronics industry (e.g., MPEG, CD, DVD) have been developed by participants in patent pools. Such pools allow competitors to achieve efficiencies by aggregating their patents for purposes of licensing and enforcement. As such, pools can achieve procompetitive benefits such as lowering transaction costs and reducing royalty stacking by multiple independent licensors. ${ }^{25}$ But in order to achieve these efficiencies, many commentators and

\footnotetext{
${ }^{18}$ For example, the Allied Tube and Hydrolevel U.S. Supreme Court cases prompted a number of SDOs to adopt "due process" policies, and the highly publicized litigation involving Rambus prompted a number of changes and clarifications to SDO patent policies. See ABA 2007, Preface.

${ }^{19}$ In the United States, private parties may request a "business review letter" from the DOJ.

${ }^{20}$ IEEE 1992, § 9.

${ }^{21}$ IEEE 1994, § 6.3.1 (emphasis added).

22 IEEE 1995, § 5 .

${ }^{23}$ IEEE 2005, § 6.3.2.

${ }^{24}$ IEEE 2007, § 6.1. IEEE's 2007 policy was controversial due to its introduction of "ex ante" disclosure procedures by which members could disclose maximum royalty rates prior to the adoption of a standard. See Chapter 15 and Contreras 2013a.

${ }^{25}$ See Gilbert 2010a, 21; Gilbert 2010b, Part III.A.
} 
enforcement agencies concur that the patents included in a pool should generally be complementary and not substitutes for one another. ${ }^{26}$

\section{a) Essentiality as Complementarity}

Complementary technologies are those that are independently required in order to achieve a stated purpose, such as compliance with a particular standard. When patents covering complementary technologies are combined in a pool, the pool acts to reduce transaction costs associated with licensing individual patents from diverse patent holders. Such pools also enable the clearing of blocking positions and the elimination of patent "thickets" that could reduce competition and innovation. But when a pool aggregates patents covering technologies that may be substituted for one another, such as patents covering different standards, innovation may be stifled. ${ }^{27}$ For example, if patents covering standards $A$ and $B$ are licensed separately, then the backers of standard $B$ will be motivated to improve standard B to compete for users with standard A. If standard A achieves broad market acceptance in a typical "standards war", then there will be little or no market for patents covering standard B. As a result, the developers of both standards $A$ and $B$ will strive to outperform the other in healthy market competition. If, on the other hand, the patents covering standards $A$ and $B$ are included in a pool, the developers of standard $B$ will have little incentive to improve $B$ in relation to $A$, as there is not a competitive market for licensing $B$ independently from $A$. So long as users license the pooled patents, the backers of both standards will earn revenue, and competition and innovation will suffer. Thus, as noted above, both commentators and enforcement agencies have largely concluded that patent pools should contain only patents that are essential to the standard that is the subject of the pool.

This precept was critical to the U.S. Department of Justice (DOJ) in its business review of patent pools covering the MPEG-2 and DVD standards in the late 1990s and early 2000s. As Gilbert notes in Chapter 8, the DOJ, in deciding not to bring enforcement actions against these pools, emphasized the importance of including only patents essential to comply with the relevant standards. ${ }^{28}$ And, in the context of these pools, the DOJ viewed "essential" as meaning that "there is no technical alternative" to any of the patents included in the pool. ${ }^{29}$ Thus, the DOJ explains in its 1997 MPEG-2 letter:

The limitation of the Portfolio to technically essential patents, as opposed to merely advantageous ones, helps ensure that the Portfolio patents are not competitive with each other and that the Portfolio license does not, by bundling in non-essential patents, foreclose the competitive implementation options that the MPEG-2 standard has expressly left open. $^{30}$

${ }^{26}$ See Shapiro 2001, 134; Gilbert 2010a, 4, Gilbert 2010b; DOJ 1997-MPEG Letter; DOJ 1998-DVD3C Letter; DOJ 1999-DVD6C Letter.

${ }_{28}^{27}$ Shapiro 2001, 134

${ }^{28}$ DOJ 1997-MPEG Letter; DOJ 1998-DVD3C Letter; DOJ 1999-DVD6C Letter. But as discussed in Chapter 8, the Court of Appeals for the Federal Circuit in Princo seemingly softened the requirement that only essential patents be included in pools when failing to do so does not result in competitive harm. Princo Corp. v. Int'l Trade Comm'n (Fed. Cir. 2010, p.1338).

${ }_{30}^{29}$ DOJ 1997-MPEG Letter, 9.

${ }^{30}$ ld. at 10. 
The importance of excluding substitute technologies and patents from pooling structures is best illustrated in the DOJ's review of the $3^{\text {rd }}$ Generation Partnership Project (3GPP) pooling arrangement. The 3GPP (discussed in detail in Chapter 3) was formed as an over-arching organizational framework for five competing $3 G$ wireless telecommunications standards (CDMA-2000, W-CDMA, TD-CDMA, TDMA-EDGE and DECT). Under this framework, patents essential to each standard would be separately pooled and licensed. While 3GPP offered a number of common administrative services to the individual pool operators, ${ }^{31}$ both licensing and enforcement of the five pools' patents was handled without coordination by 3GPP or among the five pools. The DOJ approved of this approach, citing evidence that the five $3 G$ standards were in competition with each other and that the continuation of this competition was likely under the proposed arrangement. ${ }^{32}$

Despite these statements from DOJ, at least one judicial decision in the U.S. suggests that the exclusion of patents covering all substitute technologies from a patent pool is not an absolute requirement for avoiding antitrust liability. In Princo v. ITC and related cases, ${ }^{33}$ the Federal Circuit held that Philips did not commit patent misuse because one patent included in a pool covering the CD-R/CD-RW standards was not technically essential to the standard. The court reasoned that because the patent claimed technology that Philips and Sony originally thought, in good faith, might be essential to the standards, but which was ultimately not useful to either the CD standards or any other commercial technology, the requisite elements of patent misuse were not present. Though the court declined to rule on some antitrust aspects of the case, it also acknowledged that a patent pool could provide procompetitive benefits even if it included one or more non-essential patents. ${ }^{34}$

While most standards developed within SDOs are not the subject of patent pools, ${ }^{35}$ the DOJ's analysis of pooling arrangements has proven influential to SDO policy makers.

\section{b) Validating Essentiality - Costs and Benefits}

Given the importance of determining the essentiality of patents to be included in a standards-based patent pool, most such pools conduct a rigorous analysis to verify whether or not patents are essential to the standard in question. In many cases, this analysis is conducted by an independent expert. Such an independent review mechanism was viewed with approval by the DOJ in its 1997 MPEG-2 business review letter, in which it observed that "[t]he continuing role of an independent expert to assess essentiality is an especially effective guarantor that the Portfolio patents are complements, not substitutes." 36

This being said, independent essentiality experts do not come cheap. As noted by the DOJ in its MPEG-2 letter, the designated expert "reviewed approximately 8,000 United States patent abstracts and studied about 800 patents belonging to over 100 different

${ }^{31}$ Among other things, 3GPP offered its members a common methodology for royalty calculation and a standard set of licensing terms. DOJ 2002-3GPP , 10.

${ }^{32} I d$.

${ }^{33}$ U.S. Philips Corp. v. ITC (Fed. Cir. 2005, p.1190-91); Princo Corp. v. Int'l Trade Comm'n (Fed. Cir. 2009, p.1320).

${ }_{35}^{34}$ For a more detailed discussion, see Chapter 8.

${ }^{35}$ Contreras 2013b.

${ }^{36}$ DOJ 1997-MPEG Letter, 10. 
patentees or assignees. ${ }^{\text {"37 }}$ The cost of patent essentiality review by independent experts (typically specialized patent attorneys) has been estimated by Mattioli and Merges (2016) at $\$ 7,500$ per patent, ${ }^{38}$ and by Régibeau et al (2016) at 2000 Euro per patent if conducted internally, and 9000 Euro per patent if conducted by an external firm. ${ }^{39}$ Merges and Mattioli (2016) estimate that the initial essentiality analysis for the establishment of the MPEG audio pool, which included approximately 700 patents, was $\$ 5.25$ million. $^{40}$ And in a recent court filing, Ericsson estimated that an essentiality assessment of its portfolio of 2,600 SEP families pertaining to ETSI's 2G, 3G and 4G standards would have cost approximately $\$ 26$ million. $^{41}$

Costs in this range are among the reasons that most technology standards are developed in the SDO environment, in which patent essentiality determinations are made by patent holders with no external verification, ${ }^{42}$ rather than within pooling structures. ${ }^{43}$

\section{B. The Many Meanings of Essentiality}

SDO essentiality requirements are primarily creatures of policy language. As such, different SDOs may define essentiality differently ${ }^{44}$ Bekkers and Updegrove (2012) identify thirteen different features of SDO essentiality definitions that varied considerably over the ten SSOs they studied. ${ }^{45}$ This section explores some of the variants that arise in SDO definitions of essentiality and offers guidance regarding their usage and interpretation.

\section{Claims versus Patents}

Though much of the literature relating to standardization refers to "patents" that may be essential to practice or implement a standard -- hence the ubiquitous term "standardessential patent" or SEP - it is more accurate in such discussions to refer to essential patent claims rather than entire patents. ${ }^{46}$ Patents often contain dozens of different claims, ${ }^{47}$ some of which may cover technology included in a standard, and others of which may not.

While this distinction may, at first, seem esoteric, it can have significant implications for licensing. For example, suppose that a patent has 20 claims, one of which is essential to implement a standard, but the other 19 of which are not. Under the rules of the relevant $\mathrm{SDO}$, what is the patent holder required to license to implementers of the standard?

\footnotetext{
${ }^{37}$ Id. at $4-5$.

${ }^{38}$ Merges \& Mattioli 2016, 25.

39 Régibeau et al. 2016, 50.

${ }^{40}$ The MPEG audio pool administered by Via Licensing is distinct from the MPEG-2 pool administered by MPEG-LA, which was the subject of the DOJ's MPEG-2 business review letter.

${ }^{41}$ Ericsson's Redacted Trial Brief, TCL Communication Tech. Holdings, Ltd. v. Telefonaktiebolaget LM Ericsson (C.D. Cal. 2017)

42 See Part C. 1 below.

${ }^{43}$ Contreras 2013b.

44 The same holds true for patent pools. See DOJ-FTC 2007, 74-75 (noting that each patent pool that sought a buseinss review letter from the DOJ used a slightly different definition of essentiality).

${ }^{45}$ Some of these variations involved the degree to which copyrights and other intellectual property, in addition to patents, could be considered essential to a particular standard.

${ }^{46}$ See ABA 2007, 10 (discouraging use of the term "essential patent" in lieu of "essential claim").

47 There is no limit to the number of claims that may be included in a U.S. patent. At least three U.S. patents have been issued with more than 800 claims $(6,684,189,5,095,054,7,096,160)$, and one infamous application filed in 2003 and still pending as of this writing has more than 8,000 claims (US20030173072A1).
} 
Only the single claim that is essential to the standard, or all 20 claims of the patent, including those that are non-essential? And if the latter, must the 19 non-essential claims also be licensed on terms that are FRAND or even royalty-free?

This question was raised in the Innovatio case, in which the defendant implementers argued that Innovatio's obligation to license an essential claim of a patent extended to the other claims. The court rejected this argument, relying on both the express language of IEEE's policy, as well as general principles of patent law.

[T]he Defendants contend that Innovatio is obligated to license entire patents on RAND terms, rather than merely individual patent claims. Accordingly, the Defendants assert that the RAND commitment applies to an entire patent if any claim in the patent is standard-essential. That argument gains some support from the Letters of Assurance from Innovatio's predecessors, some of which promise to license "patents". The problem, however, is that the IEEE Bylaws, which the parties have agreed define the terms of Innovatio's RAND commitment, explicitly provide that "[a]n Essential Patent Claim does not include . . . any claim other than that set forth above even if contained in the same patent as the Essential Patent Claim." The IEEE Bylaws therefore plainly contemplate that some claims, but not others, in a particular patent may be standard-essential.

More generally, patent law looks to individual claims to define the scope of a patent right. As the Federal Circuit has explained, "[a] patent is infringed if any claim is infringed ... for each claim is a separate statement of the patented invention." Pall Corp. v. Micron Separations, Inc., 66 F.3d 1211, 1220 (Fed. Cir. 1995). Given that basic attribute of patent law, the promise to license any standard-essential patent must be interpreted as a promise to license only the standard-essential claims, the basic unit for evaluation of any patented invention. The court will therefore evaluate each patent claim separately for standard-essentiality. ${ }^{48}$

The court's reasoning in Innovatio is sensible, though to the extent that it relies on the specific language of the IEEE policy, its applicability to SDOs with different policy language is limited. Even so, it would appear unreasonable to argue that claims of a patent that are non-essential to a standard should be licensed simply because the patent contains other claims that are essential, even when an SDO's policy speaks only to patents and not to patent claims.

\section{Commercial versus Technical Essentiality}

\section{a) A Matter of Degree?}

One major divide among SDO patent policies is whether they define an "essential" patent claim as covering a technology that must, as a technical or engineering matter, be included in a product implementing a standard (technical essentiality) or whether that patented technology, though not strictly required as a technical matter, is the only commercially feasible way that the standard can be implemented (i.e., considering

${ }^{48}$ In re Innovatio IP Ventures, LLC Patent Litig. (N.D. III. 2013, 936-37) (some internal citations omitted). 


\section{Essentiality}

factors such as manufacturing cost, efficiency, reliability, manufacturability, etc.) (commercial essentiality). ${ }^{49}$

For example ${ }^{50}$ suppose that a municipal electrical standard specifies a range of tolerances (pressure, temperature, corrosion resistance, puncture resistance, etc.) for wiring conduits. Such conduits are typically made from aluminum, though other materials could also be used to make such conduits. Thus, a patent covering the use of aluminum conduits for wiring would not be technically essential to the standard, as one could use various other materials. But suppose that the only alternative material that met the other tolerance requirements of the specification were gold. Aluminum conduit costs an average of $\$ 0.15$ per meter, while gold conduit, if such a thing were ever made, would cost $\$ 2,000.00$ per meter. Under this scenario, a patent covering aluminum conduit might no longer be considered technically essential to the standard, as gold, technically speaking, could also be used to make compliant conduits. Nevertheless, given these two alternatives, there is no commercially feasible alternative to aluminum. Thus, when the only technical substitute for aluminum conduit is significantly more costly, a patent covering the use of aluminum conduit would likely be commercially essential to the standard.

But what if, in addition to aluminum and gold, polyvinyl chloride (PVC) is also a suitable material for conduit which meets all the requirements of the specification. PVC costs \$0.45 per meter: three times more than aluminum, but far less than gold. Is PVC, at three times the cost of aluminum, a commercially feasible substitute for aluminum? If so, is an aluminum conduit patent still commercially essential to the implementation of the conduit standard? What if the cost of PVC conduit dropped to $\$ 0.25$ per meter? Or to $\$ 0.16$ ? Just how different must the qualities and pricing of a substitute technology (PVC) be before another technology (aluminum) is no longer considered commercially essential to the standard?

This question of degree must be factored into the analysis by SDOs deciding how to define essentiality. While technical essentiality may seem rather unforgiving and unfairly exclude some patents from the reach of the SDO's policy (e.g., a patent on aluminum conduit, when gold exists as a technically-, though not commercially-feasible, alternative), the virtually limitless gradations of pricing, quality and availability that factor into commercial manufacturing decisions could make determinations as to commercial essentiality hopelessly fraught. The next section discusses the design choices that several SDOs have made as between commercial and technical essentiality.

\section{b) SDO Policies: Commercial versus Technical Essentiality}

SDO patent policies are divided as to whether they consider the essentiality of a patent to a standard to mean technical or commercial essentiality. In a 2012 survey conducted by Bekkers and Updegrove, only two of ten SDO policies examined used a definition of "commercial" rather than "technical" essentiality, though only one (ETSI, discussed below) expressly rules out commercial factors in determining essentiality. ${ }^{51}$

${ }^{49}$ ABA 2007; Bekkers \& Updegrove 2012; Contreras 2013b; Kesan \& Hayes 2014.

${ }^{50}$ This example is inspired by the dispute over electrical wiring conduit made famous by the Supreme Court's Allied Tube (U.S. 1988) decision. Other illustrative examples of essentiality in standard-setting can be found in ABA 2007, 18-19 (alarm functionality) and Kesan \& Hayes 2014, 243-44 (slide-to-unlock).

${ }^{51}$ Bekkers \& Updegrove 2012, 35 Table 4. 


\section{Essentiality}

In considering the effect of these policy variations, as a general rule more patents will be considered essential to a standard (and hence disclosed or licensed) under a commercial essentiality approach than under a technical essentiality approach. ${ }^{52}$ Thus, in the conduit example above, a commercial essentiality approach results in an aluminum conduit patent being considered essential (and disclosed/licensed) even though gold may also be used to make conduit (as gold conduit is commercially impractical due to its relative cost), whereas a technical essentiality approach results in the aluminum conduit patent not being essential, as gold could technically act as a substitute (albeit an expensive one).

As discussed in Part A.1.c above, since its first interim patent policy was approved in 1993, ETSI has adhered to a technical essentiality approach. In each of its policies ETSI has stipulated that in order for a patent to be deemed essential to an ETSI standard, it must not be "possible" to make, use or sell a standardized product without infringing the patent. This analysis is conducted solely in terms of technical possibility, "taking into account normal technical practice and the state of the art generally available at the time of standardization". ${ }^{33}$ Conversely, ETSl's policy makes it clear that "commercial grounds" (i.e., the commercial impracticality of a technical substitute) are not valid bases for disregarding theoretically feasible technical substitutes for the patented technology. This construction of essentiality is designed to limit the number of patents covered by ETSI's patent disclosure and licensing requirements, possibly due to ETSI's establishment as the developer of mandatory, pan-European telecommunications standards which would be adopted by every national network operator and its respective equipment suppliers. ${ }^{54}$

IEEE, on the other hand, has since it first introduced a definition of essentiality to its patent policy in 2007, used a commercial essentiality approach. IEEE's definition of "Essential Patent Claim" includes any patent claim, the practice of which is necessary to implement an IEEE standard, but only if at the time of the standard's approval "there was no commercially and technically feasible non-infringing alternative". ${ }^{55}$ The meaning of IEEE's commercial essentiality definition was discussed at length by the court in Innovatio, in which the essentiality of 168 different patent claims to IEEE's 802.11 standards was challenged. The court confirmed the interpretation of IEEE's commercial essentiality requirement, reasoning that "even if some prohibitively expensive alternative existed when the standard was approved, a claim may still be [essential], because no alternative was 'commercially' feasible." 56

Policies of large, sophisticated SDOs such as ETSI, ANSI and IEEE specify, with varying degrees of clarity, whether essentiality should be taken to mean technical or commercial essentiality. However, most SDOs are not so explicit. In the Bekkers and Updegrove study mentioned above, seven of ten major SDOs did not explicitly state whether "essential" meant technical or commercial essentiality, leaving the researchers to interpret these polices based on other textual clues. ${ }^{57}$ In the absence of contrary policy

52 See ABA 2007, 18. Various commentators have weighed in regarding the optimal definition of essentiality that should be adopted by SDOs. See, e.g., Shapiro 2001, 136 ("necessary to comply" with the standard); Lemley 2002, 1959 ("necessary as a practical matter"); Kesan \& Hayes 2014, 242-43 (discussing various options).

${ }^{53}$ See Part A.2.c, above.

${ }^{54}$ This result may have been driven by the fear among patent-holding equipment manufacturers (primarily from the U.S.) that large numbers of their patents, which may also have been applicable to non-ETSI standards, could have been captured by a broad definition of essentiality and, hence, subjected to ETSI's disclosure and FRAND licensing rules. See Chapter 9; Bekkers Verspagen \& Smits 2002, 173; Iversen 2001, 74.

55 IEEE 2016, § 6.1.

${ }^{56}$ In re Innovatio IP Ventures, LLC Patent Litig. (N.D. III. 2013, 938).

${ }^{57}$ Bekkers \& Updegrove 2012, 40. 
language, should technical essentiality generally be assumed $?^{58}$ It is not so clear that this approach is desirable, particularly given the absurd scenarios (such as the gold conduit example) that can arise when a strict technical essentiality standard is applied.

Perhaps a more reasonable approach, at least when such terms must be interpreted in litigation, is to look to the understandings and expectations of the individual participants in the SDO. This approach, which has been used successfully to interpret the meaning of other provisions of ambiguous SDO patent policies, ${ }^{59}$ can establish how such policy terms are interpreted and utilized by participants on an operational basis, perhaps the most important functions of an SDO's policies.

\section{c) Patent Pools, Antitrust and Commercial Essentiality}

As noted in Part A.2 above, SDO essentiality requirements are primarily creatures of SDO policy language. This predominantly textual approach differs from that used with respect to patent pools, in which the essentiality requirement for pooled patents addresses antitrust compliance considerations. Nevertheless, given the close relationship between standards developed by members of patent pools and those developed within SDOs, it is both desirable and unavoidable that judicial and agency interpretations rendered with respect to essentiality of pooled patents should inform the interpretation of essentiality within SDO policies. As discussed below, the DOJ, in reviewing proposed patent pools for potential antitrust enforcement, has approved pooling arrangements that use both technical and commercial essentiality approaches. ${ }^{60}$

When assessing the potential competitive benefits and harms of patent pools covering technical standards, the DOJ has considered whether a pool contains only patents that are complementary to one another (generally procompetitive), or whether substitute technologies are encompassed within the pool (often anticompetitive). ${ }^{61}$ As explained by the DOJ and FTC, "pools consisting only of complementary patents are least likely to prove anticompetitive." ${ }^{\prime 2}$ By the same token, the DOJ has stated that inclusion in a pool of substitute patents could devolve into nothing more than a "price-fixing mechanism." This notion of complementarity, or lack of substitutability, is, in the context of pool analysis, generally equated with essentiality. That is, an essential patent is one that has no substitutes, however those may be defined.

In its 1997 MPEG-2 business review letter, the DOJ reviewed a proposed pool in which the members defined essentiality in technical terms, defining it as the absence of "technical alternative[s]" to any of the patents included in the pool. ${ }^{64}$ Likewise, in its 2002 3GPP business review letter, the DOJ reviewed a set of proposed pools in which included patents were required to be "technically essential" ${ }^{65}$ In both of these letters,

\footnotetext{
${ }^{58}$ Kesan \& Hayes $(2014,244)$ advocate such an interpretive approach.

59 See Contreras 2017 (discussing how the norms and expectations of SDO participants have been used to establish obligations relating to patent disclosure in SDOs in the absence of clear policy language, and even in the presence of contradictory policy language, in cases such as Rambus (FTC) and Qualcomm v. Broadcom).

60 In discussions of patent pools, the term "economic" essentiality is sometimes used in lieu of "commercial" essentiality. See DOJ-FTC 2007, 75.

${ }^{61}$ See DOJ-FTC 2007, 77

${ }^{62} l d$. Despite the general suspicion with which the DOJ appears to view pools containing substitute patents, the DOJ and FTC have noted that there may be cases in which the inclusion of patents covering substitute technologies within a pool may have procompetitive justifications. Id. at 78 .

${ }^{63}$ DOJ DVD-6C Letter (1999), 12.

${ }^{64}$ DOJ MPEG Letter (1997), 9.

${ }^{65}$ DOJ 3GPP Letter (2002), 6.
} 
the DOJ approved of the mechanisms for including patents in the proposed pools on the basis of their technical essentiality.

In other cases, however, the DOJ was asked to review proposed patent pools in which elements of commercial essentiality were introduced. Thus, in its 1999 DVD-6C letter, the agency approved a pool in which patents were deemed to be essential to the DVD standard if they were "necessarily infringed" by implementing the standard in a product or if there was "no realistic alternative" to the use of the patented technology in implementing the standard. ${ }^{66}$ While language requiring that a patent "necessarily" be infringed in order to be considered essential implies technical essentiality, the language that speaks to the absence of realistic alternatives to the patented technology suggests commercial essentiality. That is, even though a patented technology might in theory be replaced by another technology that complies with the standard, the patented technology will be considered essential if it has no "realistic" alternatives. As represented by the applicant, the independent expert engaged to assess the essentiality of patents being considered for inclusion in the pool interpreted "realistic" to mean "economically feasible" and excluded from the pool patents as to which economically feasible alternatives existed. ${ }^{67}$ The DOJ accepted this representation but warned that if the expert, over time, interpreted "realistic" more broadly to encompass patents as to which economically feasible alternatives exist, serious questions would arise regarding the pool's effect on competition.

Nine years later, in its 2008 RFID business review letter, the DOJ considered a pool that explicitly contemplated commercial considerations in its essentiality criteria. In that pool, a patent was considered essential if it was "necessarily infringed" by a product implementing the standard (technically essential), or if "a license [was] necessary as a practical matter because there are no economically viable substitutes to [m]ake, use or sell" products complying with the standard. ${ }^{68}$ In assessing the economic viability of substitutes, factors such as "production or design costs, consumer preferences, or other reasons" could be considered. ${ }^{69}$ Again, the DOJ approved of this approach, provided that it is applied "scrupulously and independently". ${ }^{70}$

\section{Essentiality of Mandatory, Optional and Alternative Technologies}

Many standards contain portions that are mandatory for compliance, as well as portions that are optional. In general, optional portions of standards may either be truly optional (included or omitted without consequence to compliance) or alternative (one of two or more approaches must be selected in order to comply with the standard). ${ }^{71}$ In addition, a standard may describe "enabling technologies" which may be necessary to comply with the standard, but which are not part of the standard itself. ${ }^{-2}$ Though the precise definition of each of these terms will be dependent on the language of the relevant SDO policy, the court in Innovatio recognized as a rule of thumb that mandatory portions of a standard

${ }^{66}$ DOJ DVD-6C Letter (1999), 3.

${ }^{67}$ Id. at 12 .

${ }^{68}$ DOJ RFID Letter (2008), 4.

69 Id. at 9 .

${ }^{70} / d$.

${ }^{71} \mathrm{~A}$ more comprehensive discussion of these options, as well as other nomenclature systems (normative versus informative portions of a standard) are discussed in ABA Manual (2007, 16-18). Kesan \& Hayes (2014, 241) suggest approach in which claims that are essential to mandatory portions of a standard are termed "core essential" and claims that are essential to optional portions of a standard are termed "noncore essential".

${ }^{72}$ Enabling technologies, as defined in the IEEE policy, are discussed in detail in In re Innovatio IP Ventures, LLC Patent Litig. (N.D. III. 2013, 937-38). 


\section{Essentiality}

are often designated by the term "shall", whereas optional portions are often designated by the terms "may" or "should". 73

To illustrate the use of these terms, in the wiring conduit example used above, the standard may specify "a cylindrical wiring conduit $5 \mathrm{~cm}$ in diameter and able to withstand internal pressure of 100 psi". The specified diameter and pressure tolerances are mandatory components of the standard. The standard may go on to state that "such conduit may be comprised of aluminum or PVC material". Here, aluminum and PVC are alternatives within the standard: neither one is strictly required, but one of the two materials, and no other, must be chosen. On the other hand, the phrase "such conduit may be marked with a water-resistant coating of any color" is truly optional. And, finally, a requirement that "the conduit must be suitable for testing by an ASME-certified leakage detection system" mentions a piece of external equipment (the detection system) which is not specified by the standard, but which is necessary for use of the standardized conduit. The ASME-certified detection system is an enabling technology.

SDO policies will often specify whether, in order to be "essential" a patent claim must be necessary (technically or commercially) to implement mandatory portions of a standard, or whether patent claims will also be deemed essential if they cover alternative or optional portions. ${ }^{74}$ In general, patents covering enabling technologies are not considered essential to a standard referencing such enabling technology.

\section{Timing and Essentiality}

Another sometimes-overlooked consideration relating to whether a particular patent claim may be essential to a standard is the point in time at which this determination is made. As discussed in Chapter 14, the timing of this determination often triggers a patent-holder's obligation to disclose patents to an SDO and its participants, and will decide whether or not a patent must be licensed on terms specified by the SDO (i.e., FRAND or royalty-free). Some SDOs specify that the essentiality determination should be made when a standard is approved or published, or earlier, such as when a technical contribution is submitted for consideration as part of a standard. ${ }^{75}$

Timing considerations are also important in order to determine whether the patent holder has complied with its disclosure and licensing obligations. That is, whether the patent holder accurately disclosed its relevant SEPs to the SDO when required by the SDO's policy, or whether it withheld information about SEPs that it should have disclosed. Key to this determination is whether particular patents are, indeed, SEPs and thus "essential" to the relevant standard. In making this determination years after a disclosure allegedly should have been made, it is important to avoid hindsight bias and to assess the patent holder's compliance based solely on information and technical capabilities available at the time that the essentiality determination was made. This issue is discussed by the court in Innovatio in interpreting the IEEE policy:

even if one could hypothesize an alternative way to implement the

\footnotetext{
${ }^{73}$ In re Innovatio IP Ventures, LLC Patent Litig. (N.D. III. 2013, 941-42).

${ }^{74}$ For example, ETSI's patent policy treats patents covering alternative implementations as essential: "where a standard can only be implemented by technical solutions, all of which are infringements of IPRs, all such IPRs shall be considered essential." ETSI 2016-Policy, § 15(6).

${ }^{75}$ See ABA 2007, 19. The ETSI policy provides that the essentiality determination is made at the time of the required declaration. ETSI 2016-Policy, § 4.1.
} 
standard, a claim is still standard-essential if that hypothetical implementation was not technically feasible when the standard was approved ... If later technological development creates another, noninfringing means to comply with the standard, a patent claim is still standard-essential. $^{76}$

Thus, "later technological development" is not relevant to the determination of essentiality at the time specified by the SDO policy (in the case of IEEE, the time that the proposed standard was approved).

Some policies do not expressly specify a time at which essentiality must be determined, but do require that patent disclosures or licensing offers be made a specific time (e.g., as soon as practical during standardization, prior to balloting of a technical proposal, etc.) In these situations, the essentiality determination should be interpreted to be made at the time the specified action is required.

\section{Essentiality and Over-Declaration}

Whatever definition of essentiality is adopted by an SDO, the actual determination whether a particular patent is essential to a standard is initially left to the patent holder. ${ }^{77}$ Due to resource and staff constraints, SDOs, unlike patent pools (discussed above) rarely review or validate their participants' determinations of essentiality. In fact, some SDOs expressly prohibit internal working groups from assessing the applicability of particular patents to their technical output, and stipulate that the representations of the disclosing patent holder should be taken at face value. ${ }^{78}$ Thus, whether a patent holder is obliged under an SDO policy to disclose its essential patents to the SDO or to license its essential patents to others, the identification of which of patents are, indeed, essential, is unilaterally made by the patent holder, subject only to a contravening determination in litigation. This situation has led to what many commentators have criticized as widespread "over-disclosure" or "over-declaration" of patents claimed to be essential to standards. ${ }^{79}$

\section{Factors Leading to Over-Declaration}

Given that patent holders often compute royalties based, at least in part, on the number of patents being licensed, there is a clear commercial incentive for patent holders to identify as many patents as possible as "essential" to a given standard. But opportunistic royalty maximization is not necessarily the only, or even the primary, cause of overdeclaration of patents to an SDO. Rather there are several external and internal factors that could drive even "honest" patent holders to declare the essentiality of patents that may eventually be found not to be essential to particular standards.

First, and most importantly, is the large disparity between penalties for under-declaring versus over-declaring patents essential to a standard. As seen in cases such as Wang

\footnotetext{
${ }^{76}$ In re Innovatio IP Ventures, LLC Patent Litig. (N.D. III. 2013, 938).

${ }^{77}$ I say "initially" because a determination of essentiality may always be challenged in court, as discussed in Part $\mathrm{D}$ below.

${ }^{78}$ See, e.g., IEEE 1995, § 6.3.2 ("While standards may include the known use of patents if there is technical justification, the working group should not attempt to determine whether or not a patent applies. The working group shall accept the view of the patent holder."). Contreras 2017.

${ }^{79}$ See, e.g., Lemley 2007, 157; Contreras 2013b, Part I.B.2 (The Dilemma of Over-Disclosure); Bartlett \&
} 


\section{Essentiality}

v. Diebold, In re. Dell, Broadcom v. Qualcomm and In re. Rambus, Inc., patent holders face serious liability for violating an SDO's requirement that essential patents be disclosed, including claims of anticompetitive behavior, deceptive conduct and fraud. ${ }^{80}$ As exemplified by Dell, the penalties for such failures to disclose could result in the unenforceability of undisclosed patents, even if such patents are essential to the relevant standard. ${ }^{81}$ Conversely, there appear to be few legal or regulatory penalties associated with declaring too many patents as essential to a standard.

In other words, patent holders may disclose to an SDO patents that are not actually essential, or even relevant, to a standard with few legal or practical consequences. ${ }^{82}$ Accordingly, patent holders involved in standards development have a strong incentive to disclose to an SDO, and make FRAND commitments with respect to, all patents that have even a remote possibility of being relevant to a standard.

This natural incentive to seek to avoid liability for under-disclosure is augmented by genuine uncertainty regarding the scope of some patent claims, which, depending on how broadly they are drafted and interpreted, may or may not cover particular aspects of a standard. Moreover, disclosure of essential patents is often required before a standard is approved and finalized by an SDO. As a result, the claims of patents that are declared essential to a draft standard may or may not be essential to the version of the standard that is ultimately approved, or to its subsequent versions. Finally, to the extent that SDOs require the disclosure of patent applications in addition to issued patents, the scope of the issued patent's claims may not even be known at the time a patent is declared as essential to a standard. ${ }^{83}$

Over-declaration is not inevitable, and it is certainly possible that some patent holders may wish to limit the number of patents that they declare to be essential to a standard in order to insulate such patents from FRAND licensing obligations (i.e., to license those non-essential patents at rates that are higher than FRAND, or not to license them at all). ${ }^{84}$ This tactic is even more likely when an SDO has adopted a policy of royalty-free licensing. For example, in Lotes v. Hon Hai, ${ }^{85}$ it was alleged that Chinese contract manufacturer Foxconn violated a royalty-free licensing commitment made with respect to patents covering the USB 3.0 standard, when it claimed that such patents were not essential to the standard. In most cases, however, given the relatively unbounded nature of FRAND licensing rates and the severe penalties for failing to disclose standards-essential patents, it seems unlikely that patent holders would intentionally withhold patents of potential relevance to a standard in order to license them on terms that are explicitly not FRAND.

${ }^{80}$ See Chapters 4 and 16, discussing liability for failure to disclose in cases such as Qualcomm Inc. $v$. Broadcom Corp. (Fed. Cir. 2008, 1008) ("silence in the face of a duty to disclose patents in a standard-setting organization"); Rambus, Inc. (F.T.C. 2006, *53) (liability for alleged concealment of patents in face of disclosure duty); Dell Computer Corp. (F.T.C. 1996) (consent decree settling alleged failure to disclose patent to standards body).

${ }^{81}$ Dell Computer Corp. (F.T.C. 1996). See also Contreras 2011.

${ }^{82}$ See Contreras 2013b, n.51 ("It is possible that intentional over-disclosure could support a claim of fraud or deception, especially if the patent holder then sought to charge royalties on patents that were not essential to the standard. However, such a case has not yet, to my knowledge, arisen.").

${ }^{83}$ Some SDOs, such as IETF, have attempted to address the issue of claim amendments between the time of disclosure of a patent application and issuance of the patent (see IETF BCP79) but in practice few patent holders have submitted such updates.

${ }^{84}$ See Shapiro 2001, n.25.

${ }^{85}$ Lotes Co. v. Hon Hai Precision Industry Co. (S.D.N.Y. Feb. 6, 2013). 


\section{Essentiality}

\section{Quantifying Over-Declaration}

There is evidence that these incentives to over-declare patents to SDOs have, indeed, resulted in significant over-declaration. For example, in an often-cited series of studies by Fairfield Research, only $28 \%, 29 \%$ and $50 \%$ of patent families declared "essential" to ETSI's 2G, 3G and 4G wireless telecommunications standards, respectively, were actually essential to implementation of those standards. ${ }^{86}$ Cyber Creative (2013) independently evaluated a sample of 2,129 SEPs declared essential to the LTE standard (representing $36 \%$ of the 5,919 total declared SEPs). It found that $56 \%$ of the sampled SEPs were "truly" essential to the standard, while $29 \%$ were partially essential and $15 \%$ were not essential at all. The investigators then calculated the ratio of essential to nonessential declared SEPs for each major contributor to the standard, finding that several firms including Apple, Alcatel-Lucent, Freescale and Nortel had essentiality ratios of $40 \%$ or less, while ZTE, CATT, NTT DoCoMo and InnovativeSonic had ratios above $80 \%$. The average essentiality ratio observed was $56.6 \%$, or $53.8 \%$ when only issued patents were considered. Interviews conducted by Blind et al. (2011) and Régibeau et al. (2016) also point to widespread over-declaration of patents at SDOs and identify overdeclaration as a significant area of concern for stakeholders in standardization.

While the factors leading to over-declaration can be understood, it must also be recognized that over-declaration distorts the overall picture of patent coverage of particular standards. Thus, a standard covered by 1,000 patents may look very different, from a royalty standpoint, than a standard covered by 250 patents. Moreover, the actual technical value contributed by those patent holders who have over-declared most aggressively may be greatly overstated and reduced or eliminated entirely if essentiality were assessed more stringently.

Typically, the fact that over-declaration has occurred would not become apparent until a patent holder sought to enforce its patents against a standard implementer, at which point a court would decide whether those patents were infringed and/or invalid. But prior to market adoption of a standard, a vendor is confronted with the prospect of engaging in multiple time-consuming and costly negotiations to license patents that may not, in the end, actually be essential to a standard (even if the standard is ultimately successful, which is also uncertain). It may thus be rational for a vendor to adopt a "wait and see" approach and engage in licensing negotiations only with patent holders that approach it with credibly essential patents. In most cases, such approaches will occur only after the market adoption of a standard and the release of a vendor product that implements the standard.

\section{Proposals to Address Over-Declaration}

To begin to address over-declaration, Régibeau et al. (2016) have proposed a number of possible approaches, including increasing the cost of declaring SEPs, limiting the number of patents that any SSO participant may declare as essential, and instituting random essentiality testing of patents declared as essential. ${ }^{87}$

\footnotetext{
${ }^{86}$ Fairfield Resources Int'l 2010; Fairfield Resources Int'l 2008, 7; Fairfield Resources Int'l 2009, 1.

${ }^{87}$ It is not clear whether such testing would be conducted by the SSO, the SEP holder or a governmental regulator.
} 
As discussed above, patent pools often allow pool members to challenge the essentiality of patents contributed to the pool by other members. As a general rule, however, the initial essentiality determinations undertaken by pools are too costly to be practical within the context of voluntary consensus standard setting. To obtain some of the advantages of pooling, Contreras (2013b) has proposed an aggregate royalty system for SEPs termed a "pseudo-pool". Under this system, an aggregate royalty for all SEPs applicable to a particular standard would be negotiated by SDO participants. The proceeds from licensing SEPs covering the standard would be divided among SEP holders, who would be given the opportunity to challenge each others' essentiality determinations, with penalties assessed against over-declaration.

Another innovative approach was taken by IPXI, an electronic exchange that sought to enable market-based trading of unitized license rights under a portfolio of 129 patents covering the $802.11 \mathrm{n}$ standard. ${ }^{88}$ IPXI engaged an independent expert to verify the essentiality of all patents that were aggregated in its unitized license package. Despite having several innovative features, the IPXI exchange was not commercially successful and ceased operations in 2015.

\section{Challenges to Essentiality}

Challenges to claims of essentiality can be raised in patent litigation under several circumstances. First, if the asserted patents were not declared as essential to a standard developed within an SDO that imposes disclosure or licensing commitments on its participants (and their transferees), then an accused infringer may argue that the patents are essential to such a standard and that as a result (a) the patent holder violated its obligation to disclose the patents to the SDO and other participants during the standardization process, or (b) the patents should be subject to the SDO's royalty-free or FRAND licensing commitments. Conversely, an accused infringer may argue that asserted patents are not essential to a standard, thus diminishing their value and/or making the patent holder's case for proving infringement more difficult. Such disputes may also arise before patents are asserted, when a patent holder seeks to license its SEPs to the manufacturer of a standardized product and the manufacturer claims that some or all of the proffered patents are not essential to practice the standard. The outcome of such a dispute may both influence the magnitude of the royalty paid by the manufacturer, and also determine whether or not the patent holder complied with its obligations, for example, under negotiation procedures established under Huawei v. ZTE in Europe ${ }^{89}$ or the U.S. Federal Trade Commission. ${ }^{90}$ As such, disputes regarding the essentiality of patents to industry standards have become increasingly common. ${ }^{91}$

\section{Competition Law Enforcement - Sun/ETSI (EC)}

One avenue available to parties disputing the essentiality of declared SEPs is lodging a complaint with a relevant competition or antitrust law agency. Such an action was taken by a small firm called MicroElectronica in response to a patent declaration made by Sun Microsystems to ETSI with respect to the GSM standard. ${ }^{92}$ In 2000 , MicroElectronica filed a complaint with the European Commission alleging several violations by Sun of

\footnotetext{
${ }^{88}$ See Contreras 2016c.

${ }^{89}$ See Chapters 17, 25.

${ }^{90}$ See Chapter 16.

91 Additional cases are discussed briefly in Chapter 7, Part D.1.

${ }^{92}$ See Eltzroth 2008, 27; Schellingerhout 2011, 3, 5.
} 
Article 81 of the TFEU. ${ }^{93}$ Among these were allegations that Sun filed its patent declaration too late (long after standardization work had been completed) and that Sun falsely declared a non-essential patent to be essential to GSM. According to MicroElectronica, such false declarations of essentiality could have the effect of improperly influencing technology choices during standards development (i.e., driving standards toward other patented positions) and chilling downstream innovation (if product developers fear high royalty burdens from standardized technologies). In response to MicroElectronica's claim and the Commission's subsequent investigation, ETSI removed Sun's allegedly false declaration from its database and committed to clarify its patent policy. ${ }^{94}$ Sun subsequently settled with MicroElectronica. ${ }^{95}$

\section{Judicial Declaration of Non-Essentiality - Nokia v. InterDigital (UK)}

In two separate actions in the English courts, Nokia pre-emptively sought a novel judicial declaration that certain of InterDigital's declared SEPs were not essential to ETSI standards (termed a "non-essentiality declaration"). ${ }^{96}$ The first action was brought in 2004 in relation to three patents declared essential to ETSI's 2 G GSM standard ${ }^{97}$ the second was brought in 2006 in relation to 31 patents declared essential to ETSI's 3G UMTS standard. ${ }^{98}$ In both cases, the UK High Court (Patents) determined that issuing such a "negative declaration" was within the court's power and discretion.

InterDigital objected to the notion of a declaration of non-essentiality, arguing that such a judicial declaration would have no value, given that an implementer could be found to infringe a patent whether or not it was essential to a standard or merely covered a particular implementation of the standard. The court rejected this argument, noting that the status of a patent as a SEP carries potentially significant value in licensing negotiations. ${ }^{99}$

The $2 \mathrm{G}$ case was settled in 2008 prior to the issuance of the court's decision. In the $3 G$ case, however, the Patent Court ruled on the requested negative declaration in late 2007. Of the 31 patents initially asserted by InterDigital, only four remained in contention at the time of trial. Of these four, the court found only one that it deemed essential to the relevant standard. The court's analysis was based on a claim-by-claim analysis of the asserted patents against the elements of the standard. The case settled in 2008 prior to adjudication of infringement or invalidity. Nevertheless, these cases are important for establishing the availability of a judicial non-essentiality declaration in the UK courts, and may be informative for courts in other jurisdictions.

\section{Essentiality Asserted by Patentee - Unwired Planet v. Huawei (UK)}

Unwired Planet, a patent assertion entity, acquired a portfolio of more than 2,800 patents from Ericsson in 2013. In 2014, it asserted six of these patents in the UK against a group of defendants including Huawei, Samsung and Google. ${ }^{100}$ Unwired Planet claimed that five of the six patents were essential to a portion of ETSI's 4G LTE standard. Mister

\footnotetext{
${ }^{93}$ Sun/ETSI (European Comm'n, 2003).

${ }^{94}$ Schellingerhout 2011.

${ }^{95}$ Eltzroth 2008, 27.

${ }^{96}$ See Cook 2016.

${ }^{97}$ Nokia Corporation v. InterDigital Technology Corporation (EWHC 2004).

${ }_{98}^{98}$ Nokia Corporation v InterDigital Technology Corporation (EWHC 2006).

${ }^{99}$ See Cook 2016, 3.

${ }^{100}$ For a general discussion of the case, see Brodie \& Dunnill (2015).
} 
Justice Birss of the UK High Court (Patent) divided the trial into five segments, ruling in late 2015 on the first of these, which concerned a single UK patent. ${ }^{101}$ The court's decision regarding essentiality of the asserted patent hinged on the question of claim construction. In essence the parties acknowledged that if the plaintiff's construction were accepted, then the patent would be essential to the standard. ${ }^{102}$ After a detailed claim construction exercise, Birss, J. agreed with Unwired Planet's construction and concluded that the patent was essential to the standard. ${ }^{103}$

\section{Essentiality of Multiple Patents - In re. Innovatio (U.S.)}

Perhaps the most extensive judicial analysis of patent essentiality occurred in Innovatio (2013), in which the essentiality of 168 patent claims to the IEEE's 802.11 standard was disputed. ${ }^{104}$ In the case, Innovatio, the patent holder, asserted 441 claims of 23 patents against a group of wireless router users and manufacturers. In disputing the total damages potentially available to the patent holder, the defendants argued that all claims of the asserted patents were "essential" to the 802.11 standard and thereby subject to IEEE's RAND limitation on royalties. The patent holder contested the essentiality of 168 claims of the asserted patents, presumably so that it could seek royalties in excess of RAND rates with respect to those non-essential claims.

The court first established that the defendants bore the burden of proving the essentiality of asserted patent claims to the standard, as the argument as to RAND limitations on available royalties was akin to an affirmative defense. ${ }^{105}$ The court next interpreted the essentiality definitions set forth in the 2007 version of IEEE's patent policy (discussed at Part B.2 above). Among the court's key determinations regarding the policy was that a patent claim will be considered essential if "the only commercially and technically feasible way" to implement the standard is to infringe the patent and the claim "includes, at least in part, technology that is explicitly required by or expressly set forth in the standard."106 The court rejected Innovatio's argument that claims should not be deemed essential simply because they recite elements, such as enabling technologies, that are not strictly required for compliance with the standard. ${ }^{107}$

Having established the basis for assessing essentiality under IEEE's policy, the court undertook a detailed category-by-category analysis to determine whether individual patent claims covered technology that was necessary to comply with the standard. ${ }^{108}$ To break down this prodigious task, the parties classified the technology into fifteen separate categories and assessed the patent claims addressing each of these categories separately. After completing this analysis, the court found that all 168 disputed patent claims were essential to the 802.11 standard and thus subject to IEEE's RAND licensing requirements.

Though the Innovatio decision is based on an interpretation a now-superseded version of one SDO's patent policy, it offers a number of generalizable principles relating to the

101 Unwired Planet Intl. Ltd. v. Huawei Technologies Co., Ltd. (EWHC 2015).

102 Id. at $\mathbb{T} 100$.

${ }^{103}$ As of press time, other elements of this case are still pending in the UK courts and subject to appeal.

${ }^{104}$ In re Innovatio IP Ventures, LLC Patent Litig. (N.D. III. 2013).

105 Id. at 936.

${ }^{106}$ Id. at 939 .

107 Id. at 938.

${ }^{108}$ Id. at 942-57 (analyzing patents in 15 different technology categories). The court held that all 168 contested claims were essential to the 802.11 standard. 
interpretation of SDO essentiality requirements, as well as a useful roadmap for the analysis of essentiality disputes in the future.

\section{Essentiality in Top-Down Royalty Allocations - TCL v Ericsson (U.S.)}

In a case that is currently pending in the U.S. District Court for the Central District of California, Chinese smartphone manufacturer TCL has alleged that Ericsson breached its FRAND commitments by refusing to grant TCL a license to Ericsson's patents essential to ETSI's 2G, 3G and 4G standards. ${ }^{109}$ TCL asserts that it should be entitled to a license for these SEPs bearing a royalty based on Ericsson's overall share of the SEPs covering these standards. This is a so-called "top-down" royalty approach, in which the aggregate royalty attributable to a standard is based on the value of the standard to the end product in which it is implemented (here, a smartphone), and the portion of that aggregate royalty allocable to the SEP holder is determined based on its share of the SEPs covering that standard. ${ }^{110}$ TCL's expert testified that for $2 \mathrm{G} / 3 \mathrm{G}$, the maximum aggregate royalty burden should not exceed $5 \%$ of the end product price, while for $4 G$ it should not exceed $6-8 \% .{ }^{111}$ Both figures were purportedly derived from public statements made by Ericsson. TCL's experts then determined that Ericsson's share of all SEPs was $8 \%$ for $2 \mathrm{G}, 3.7 \%$ for $3 \mathrm{G}$ and $4.7 \%$ for $4 \mathrm{G} .{ }^{112}$ On this basis, TCL's experts calculate a proposed FRAND royalty rate for the requested SEP license. Not surprisingly, Ericsson contests both TCL's methodology and results. ${ }^{113}$

This case is in its early stages. However, whatever the eventual outcome, it highlights the potential importance of essentiality determinations not on a patent-by-patent basis, but on an aggregate basis in support of top-down royalty calculation methodologies. A form of top-down approach was used by the U.S. district court in Innovatio, ${ }^{114}$ as well as the Japanese IP Court in Samsung V. Apple Japan. ${ }^{115}$ To the extent that top-down approaches gain in popularity, as some commentators have suggested, ${ }^{116}$ then reliable, efficient, and cost-effective methodologies for assessing the essentiality of large numbers of declared SEPs will need to be developed.

\section{Conclusion}

As creatures of policy language, different SDO definitions of essentiality must be given interpretive deference. Nevertheless, as scholarship and case law in this area expands, a number of common themes emerge in the interpretation of essentiality requirements. One such theme is the economic equation of essentiality with non-substitutability that has arisen in the context of patent pools. Another is the blurred divide between commercial and technical essentiality. A third is the practical necessity of assessing essentiality when hundreds of potentially essential patent claims are at issue. These issues, coupled with the recognized phenomenon of over-declaration, suggests that

${ }^{109}$ TCL's Redacted Trial Brief, TCL Communication Tech. Holdings, Ltd. v. Telefonaktiebolaget LM Ericsson (C.D. Cal. 2017).

${ }_{110}$ See generally, Bartlett \& Contreras 2017 (discussing top-down royalty approach). (C.D. Cal. 2017)

111 TCL's Redacted Trial Brief, TCL Communication Tech. Holdings, Ltd. v. Telefonaktiebolaget LM Ericsson

112 Id.

113 Id. at $44-48$.

${ }_{114}$ In re Innovatio IP Ventures, LLC (N.D. III. 2013, p.*83).

${ }_{115}$ Apple Japan Godo Kaisha v. Samsung Electronics Co. (IP High Ct. of Japan 2014).

${ }^{116}$ See Bartlett \& Contreras 2017 (advocating use of a top-down royalty approach for SEP cases, implemented through the procedural interpleader mechanism); Cotter 2017, 43-44 (discussing Innovatio top-down analysis); Pentheroudakis \& Baron, 2017, 95-96 (analyzing Innovatio and other top-down approaches). 


\section{Essentiality}

more efficient, rapid and cost-effective methods for assessing essentiality may be called for. Moreover, when strict legal interpretation of policy language is likely to yield absurd results -- as when a patent is deemed non-essential because a theoretically equivalent, but impractically costly, alternative exists -- the norms and expectations of the relevant SDO participants should be taken into account.

\section{References}

American Bar Association (ABA). 2007. Committee on Technical Standardization, Section of Science \& Technology Law. 2007. Standards Development Patent Policy Manual (Jorge L. Contreras, ed., ABA Publishing).

Bartlett, Jason R. and Jorge L. Contreras. 2017. "Rationalizing FRAND Royalties: Can Interpleader Save the Internet of Things," 36 The Review of Litigation (forthcoming).

Bekkers, Rudi, Bart Verspagen and Jan Smits. 2002. "Intellectual Property Rights and Standardization: the case of GSM", 26 Telecommunications Policy 171.

Bekkers, Rudi and Andrew Updegrove. 2012. "A Study of IPR Policies and Practices of a Representative Group of Standard Setting Organizations Worldwide," Presented at National Academies of Science Symposium on Management of IP in Standards-Setting Processes. http://sites.nationalacademies.org/xpedio/groups/pgasite/documents/webpage/pga_072197.pdf.

Besen, Stanley M. 1990. "The European Telecommunications Standards Institute: A preliminary analysis," 14 Telecommunications Policy 521.

Brodie, Alexandra and Emma Dunnill. 2015 Unwired Planet's LTE SEP Found Valid, Infringed and Essential by U.K. High Court, World Intell. Prop. Report.

Contreras, Jorge L. 2011. "Equity, Antitrust and the Reemergence of the Patent Unenforceability Remedy," Antitrust Source, Oct. 2011.

--- 2013a. "Technical Standards and Ex Ante Disclosure: Results and Analysis of an Empirical Study," 53 Jurimetrics 163 Journal 47.

--- 2013b. "Fixing FRAND: A Pseudo-Pool Approach to Standards-Based Patent Licensing," 79 Antitrust Law

--- 2016c. "FRAND Market Failure: IPXI's Standards-Essential Patent License Exchange", 15 Chi-Kent Journal of Intellectual Property 419

-- 2017. "From Private Ordering to Public Law: The Legal Framework Governing Standards-Essential Patents", 30 Harv. J.L. \& Tech. 211.

Cook, William. 2016. "FRAND or foe," ManagingIP.com. Jun. $1,2016$. http://www.managingip.com/Article/1254371/FRAND-or-foe.html.

Cotter, Thomas F. 2017. "Patent Damages Heuristics," Texas Intellectual Property Law Journal (forthcoming 2017).

U.S. Dep't of Justice (DOJ). 1997-MPEG-2 Letter. Letter from Joel I. Klein, Acting Assistant Att'y Gen., Antitrust Div., U.S. Dep't of Justice, to Garrard R. Beeney, Sullivan \& Cromwell LLP (Jun. 26, 1997).

--- 1998-DVD3C Letter. Letter from Joel I. Klein, Assistant Att'y Gen., Antitrust Div., U.S. Dep't of Justice, to Garrard R. Beeney, Sullivan \& Cromwell LLP (Dec. 16, 1998) http://www.usdoj.gov/atr/public/busreview/2121.pdf.

--- 1999-DVD6C Letter. Letter from Joel I. Klein, Assistant Att'y Gen., U.S. Dep't of Justice, to Carey R. Ramos, Paul, Weiss, Rifkind, Wharton \& Garrison LLP (Jun. 10, 1999).

--- 2002-3GPP Letter. Letter from Charles A. James, Assistant Att'y Gen., Antitrust Div., U.S. Dep't of Justice, to Ky P. Ewing, Vinson \& Elkins LLP (Nov. 12, 2002).

--- 2006-VITA Letter. Letter from Thomas O. Barnett, Assistant Att'y Gen., U.S. Dep't of Justice, to Robert A. Skitol, Esq., Drinker, Biddle \& Reath, LLP (Oct. 30, 2006).

--- 2007a -IEEE-SA Letter. Letter from Thomas O. Barnett, Assistant Att'y Gen., U.S. Dep't of Justice, to Michael A. Lindsay, Esq., Dorsey \& Whitney LLP (Apr. 30, 2007)

--- 2007b. Antitrust Enforcement and Intellectual Property Rights: Promoting Innovation and Competition.

--- 2008-RFID Letter. Letter from Thomas O. Barnett, Assistant Att'y Gen., Antitrust Div., U.S. Dep't of Justice, to William F. Dolan \& Geoffrey Oliver, Jones Day (Oct. 21, 2008).

--- 2011a. CPTN Holdings LLC and Novell Inc. Change Deal in Order to Address Department of Justice's Open Source Concerns (Apr. 20, 2011). 


\section{Essentiality}

--- 2011b. Introduction to Antitrust Division Business Reviews.

--- 2012. Statement of the Department of Justice's Antitrust Division on Its Decision to Close Its Investigations of Google Inc.'s Acquisition of Motorola Mobility Holdings Inc. and the Acquisitions of Certain Patents by Apple Inc., Microsoft Corp. and Research in Motion Ltd., (Feb. 13, 2012).

--- 2013-IPXI Letter. Letter from William J. Baer, Assistant Att'y Gen., Antitrust Div., U.S. Dep't of Justice, to Garrard R. Beeney, Sullivan \& Cromwell LLP (Mar. 26, 2013).

--- 2014. Statement of the Department of Justice Antitrust Division on Its Decision to Close Its Investigation of Samsung's Use of Its Standards-Essential Patents (Feb. 7, 2014).

--- 2015-IEEE-SA Letter. Letter from Renata B. Hesse, Acting Assistant Att'y Gen., U.S. Dep't of Justice, to Michael A. Lindsay, Esq., Dorsey \& Whitney LLP (Feb. 2, 2015).

U.S. Dep't of Justice and Patent \& Trademark Office (DOJ-PTO). 2013. Policy Statement on Remedies for Standards-Essential Patents Subject to Voluntary F/RAND Commitments. http://www.justice.gov/atr/public/guidelines/290994.pdf.

U.S. Dep't of Justice \& Fed. Trade Comm'n (DOJ-FTC). 2007. Antitrust Enforcement and Intellectual Property Rights: Promoting Innovation and Competition.

Eltzroth, Carter. 2008. "IPR Policy of the DVB Project: Negative Disclosure, FRAND Arbitration Unless Pool Rules OK, Part 1," 6 International Journal of IT Standards \& Standardization Research 21.

European Comm'n. 1992. COM (92) 445 final, Communication on Intellectual Property Rights and Standardization

Fairfield Resources International. 2008 Analysis of Patents Declared as Essential to GSM as of June 6, 2007 http://frlicense.com/GSM_FINAL.pdf.

Fairfield Resources International. 2009. Review of Patents Declared as Essential to WCDMA Through December, 2008.

Fairfield Resources International. 2010. Review of Patents Declared as Essential to LTE and SAE (4G Wireless Standards) Through June 30, 2009. http://www.frlicense.com/LTE\%20Final\%20Report.pdf.

Gilbert, Richard J. 2010a. "Ties That Bind: Policies to Promote (Good) Patent Pools," 77 Antitrust Law Journal 1.

--- 2010b. "The Essentiality Test for Patent Pools," in Rochelle C. Dreyfuss, Harry First and Diane L. Zimmerman eds., Working within the Boundaries of Intellectual Property: Innovation Policy for the Knowledge Society.

GTW $\quad 2015 . \quad$ Evolution of the ANSI Patent Policy. http://www.gtwassociates.com/answers/evolutionansipolicy.html\#1969

Iversen, Eric. 2001. "Patenting and voluntary standards: the tension between the domain of proprietary assets and that of 'public goods' in the innovation of new network technologies," Science Studies, 14(2).

Kesan, Jay P. and Carol M. Hayes. 2014. "FRAND's Forever: Standards, Patent Transfers, and Licensing Commitments," 89 Indiana Law Journal 231.

Lemley, Mark. 2002. "Intellectual Property Rights and Standard-Setting Organizations," 90 California Law Review 1889.

--- 2007. "Ten Things to do About Patent Holdup of Standards (And One Not To)," 48 Boston College Law Review 149

Merges, Robert P. and Michael Mattioli. 2017. "Measuring the Costs and Benefits of Patent Pools," 77 Ohio State Law Journal (forthcoming).

Pentheroudakis, Chryssoula and Justus A. Baron. 2017. "Licensing Terms of Standard Essential Patents: A Comprehensive Analysis of Cases," JRC Science for Policy Report EUR 28302.

Régibeau, Pierre, Raphaël De Coninck and Hans Zenger. 2016. "Transparency, Predictability, and Efficiency of SSO-based Standardization and SEP Licensing," A Report for the European Commission.

Schellingerhout, Ruben. 2011. "Standard-setting from a competition law perspective," Competition Policy Newsletter Nov. 2011. http://ec.europa.eu/competition/publications/cpn/2011_1_1_en.pdf.

Shapiro, Carl. 2001. "Navigating the Patent Thicket: Cross Licenses, Patent Pools, and Standard Setting," in Adam B. Jaffe et al., eds Innovation Policy and the Economy. Massachusetts: MIT Press. 